\title{
Connexin 43 impacts on mitochondrial potassium uptake
}

\author{
Kerstin Boengler ${ }^{1}$, Elvira Ungefug ${ }^{1}$, Gerd Heusch ${ }^{2}$, Luc Leybaert ${ }^{3}$ and Rainer Schulz ${ }^{1}$ * \\ 1 Physiologisches Institut, Justus-Liebig-Universität Giessen, Giessen, Germany \\ ${ }^{2}$ Institut für Pathophysiologie, Universitätsklinikum Essen, Essen, Germany \\ ${ }^{3}$ Department of Basic Medical Sciences, Ghent University, Ghent, Belgium
}

\section{Edited by:}

Aida Salameh, Heart Centre

University of Leipzig, Germany

Reviewed by:

Klaus Groschner, University of Graz,

Austria

Aida Salameh, Heart Centre

University of Leipzig, Germany

\section{${ }^{*}$ Correspondence:}

Rainer Schulz, Physiologisches Institut, Justus-Liebig-Universität Giessen, Aulweg 129, 35392 Giessen, Germany

e-mail: rainer.schulz@physiologie. med.uni-giessen.de
In cardiomyocytes, connexin 43 (Cx43) forms gap junctions and unopposed hemichannels at the plasma membrane, but the protein is also present at the inner membrane of subsarcolemmal mitochondria (SSM). Both inhibition and genetic ablation of $\mathrm{C} \times 43$ reduce ADP-stimulated complex 1 respiration. Since mitochondrial potassium influx impacts on oxygen consumption, we investigated whether or not inhibition or ablation of mitochondrial CX43 alters mitochondrial potassium uptake. SSM were isolated from rat left ventricular myocardium and loaded with the potassium-sensitive dye PBFI (potassium-binding benzofuran isophthalate). Intramitochondrial potassium was replaced by tetraethylammonium. Mitochondria were incubated under control conditions or treated with $250 \mu \mathrm{M}$ Gap19, a peptide that specifically inhibits $\mathrm{C} \times 43$-based hemichannels at plasma membranes. Subsequently, $140 \mathrm{mM} \mathrm{KCl}$ was added and the slope of the increase in PBFI fluorescence over time was calculated. The slope of the PBFI fluorescence of the control mitochondria was set to $100 \%$. In the presence of Gap19, the mitochondrial potassium influx was reduced from $100 \pm 11.6 \%$ in control mitochondria to $65.5 \pm 10.7 \%(n=6, p<0.05)$. In addition to the pharmacological inhibition of $\mathrm{Cx} 43$, potassium influx was studied in mitochondria isolated from conditional $\mathrm{C} \times 43$ knockout mice. Here, the ablation of $\mathrm{C} \times 43$ was achieved by the injection of 4-hydroxytamoxifen (4-OHT; Cx43Cre-ER(T)/fl $+4-\mathrm{OHT})$. The mitochondria of the $\mathrm{C} \times 43^{\mathrm{Cre}-\mathrm{ER}(\mathrm{T}) / \mathrm{fl}}+4-\mathrm{OHT}$ mice contained $3 \pm 1 \% \mathrm{C} \times 43(n=6)$ of that in control mitochondria $(100 \pm 11 \%, n=8, p<0.05)$. The ablation of $\mathrm{C} \times 43(n=5)$ reduced the velocity of the potassium influx from $100 \pm 11.2 \%$ in control mitochondria $(n=9)$ to $66.6 \pm 5.5 \%(p<0.05)$. Taken together, our data indicate that both pharmacological inhibition and genetic ablation of $\mathrm{C} \times 43$ reduce mitochondrial potassium influx.

Keywords: connexin 43, mitochondria, potassium uptake, Gap19, PBFI

\section{INTRODUCTION}

Connexin 43 (Cx43) forms gap junctions between adjacent cardiomyocytes and is thus essential for cell-cell communication. Six $\mathrm{Cx} 43$ proteins at the plasma membrane assemble into a hemichannel, and hemichannels open during ischemia and thereby contribute to cell injury (Shintani-Ishida et al., 2007; Clarke et al., 2009). Additionally, $\mathrm{Cx} 43$ is present at the inner membrane of cardiomyocyte mitochondria, and cross-linking studies suggest the presence of $\mathrm{Cx} 43$-hemichannels within cardiomyocyte mitochondria (Miro-Casas et al., 2009). However, not all cardiomyocyte mitochondria contain $\mathrm{Cx} 43$. In contrast to subsarcolemmal mitochondria (SSM), interfibrillar mitochondria (IFM) lack Cx43 (Boengler etal., 2009). An analysis of the impact of Cx43 on mitochondrial function revealed reduced oxygen consumption in mitochondria in which $\mathrm{Cx} 43$ was either inhibited by $18 \alpha-$ glycyrrhetinic acid ( $18 \alpha \mathrm{GA})$ or $\mathrm{Cx} 43$-mimetic peptides or in which Cx43 was deleted by conditional knockout (Boengler et al., 2012).

Since mitochondrial potassium fluxes are important for the cardioprotection by ischemic pre- and postconditioning (O'Rourke, 2004; Boengler et al., 2011) and ischemic preconditioning depends on Cx43 (Schwanke etal., 2002), the impact of Cx43 on mitochondrial potassium uptake was studied. In permeabilized wildtype mouse cardiomyocytes, mitochondrial potassium influx was reduced by $18 \alpha \mathrm{GA}$. Also, the replacement of $\mathrm{Cx} 43$ by Cx32 - a connexin which forms channels with lower potassium conductance (Harris, 2002) - decreased the potassium influx into permeabilized murine cardiomyocytes (Miro-Casas et al., 2009). In astrocytes, which also contain mitochondrial $\mathrm{Cx} 43$, the administration of the $\mathrm{Cx} 43$ inhibitors carbenoxolone and $18 \alpha \mathrm{GA}$ reduced mitochondrial potassium uptake (Kozoriz et al., 2010).

In the present study, we investigated the importance of $\mathrm{Cx} 43$ for potassium uptake in isolated cardiac mitochondria rather than in intact cardiomyocytes. We studied potassium influx in isolated wild-type mouse mitochondria that were treated with Gap19, a novel peptide which specifically targets $\mathrm{Cx} 43$-based hemichannels. In addition, mitochondria isolated from conditional $\mathrm{Cx} 43$ knockout mice were investigated.

\section{MATERIALS AND METHODS ANIMALS}

The present study was performed with approval by the Bioethical Committee of the State of Nordrhein-Westfalen, Germany. It conforms to the Guide for the Care and Use of Laboratory Animals published by the US National Institutes of Health (NIH publication No. 85-23, revised 1996). 
A dose of $3 \mathrm{mg}$ 4-hydroxytamoxifen (4-OHT) was injected daily for five consecutive days in $\mathrm{Cx} 43^{\mathrm{Cre}-\mathrm{ER}(\mathrm{T}) / \mathrm{fl}}$ mice in which one $\mathrm{Cx} 43$ allele had been replaced by the tamoxifen-inducible Cre recombinase. The mice were sacrificed on day 11 after the first injection and mitochondria were isolated from the left ventricles. 4-OHT-treated $\mathrm{Cx} 43^{\mathrm{fl} / \mathrm{fl}}$ mice served as a control for potassium measurements, and untreated $\mathrm{Cx} 43^{\mathrm{fl} / \mathrm{fl}}$ mice were used as a control for Western blot analysis.

Experiments on the effects of Gap19 on potassium uptake were performed in SSM and IFM from C57/Bl6 mice.

\section{ISOLATION OF MITOCHONDRIA}

Subsarcolemmal mitochondria were isolated as previously described (Boengler et al., 2005). In brief, ventricles were minced in isolation buffer [in mM: sucrose 250; 4-(2-hydroxyethyl)1-piperazineethanesulfonic acid (HEPES) 10; ethylene glycol tetraacetic acid (EGTA) 1; 0.5\% bovine serum albumin (BSA); $\mathrm{pH}$ 7.4], homogenized with an Ultra Turrax, and centrifuged at $700 \mathrm{~g}$ for $10 \mathrm{~min}$. The resulting supernatant was centrifuged at $10,780 \mathrm{~g}$ for $10 \mathrm{~min}$, and the mitochondrial sediment was re-suspended in isolation buffer without BSA and centrifuged at 7,650 $\mathrm{g}$ for $10 \mathrm{~min}$. The protein concentration of the isolated mitochondria was determined using the Dc protein assay (Bio-Rad, Hercules, CA, USA) with BSA as standard. For Western blot analysis, the mitochondria were further purified by Percoll gradient ultracentrifugation (30\% Percoll in isolation buffer, $34,000 \mathrm{~g}, 30 \mathrm{~min}$ ).

Subsarcolemmal mitochondria and IFM were isolated as already described (Boengler et al., 2009). Ventricular tissue was washed in buffer A [in mM: $\mathrm{KCl} 100,3-(\mathrm{N}$-morpholino)propanesulfonic acid (MOPS) 50, $\mathrm{MgSO}_{4}$ 5, ATP 1, EGTA 1, pH 7.4] and weighed. Ventricles were minced in $10 \mathrm{ml} / \mathrm{g}$ buffer $B$ (buffer A $+0.04 \%$ BSA). The homogenate was centrifuged for $10 \mathrm{~min}$ at $800 \mathrm{~g}$ and the resulting supernatant (for SSM isolation) for $10 \mathrm{~min}$ at $8,000 \mathrm{~g}$. The sediment was re-suspended in buffer A, washed, and re-suspended in a small volume of buffer A. The sediment of the first centrifugation (used for isolation of IFM) was re-suspended in buffer $\mathrm{B}(10 \mathrm{ml} / \mathrm{g}$ tissue $)$. Nagarse $(8 \mathrm{U} / \mathrm{g})$ was added and incubated for $1 \mathrm{~min}$ on ice. The tissue was homogenized and centrifuged for $10 \mathrm{~min}$ at $800 \mathrm{~g}$. The supernatant was centrifuged for $10 \mathrm{~min}$ at $8,000 \mathrm{~g}$. The mitochondria in the sediment were re-suspended, washed in buffer $\mathrm{A}$, and finally re-suspended in a small volume of buffer A.

\section{MITOCHONDRIAL POTASSIUM INFLUX}

Mitochondria were loaded with $10 \mu \mathrm{M}$ PBFI-AM [acetoxymethyl ester of PBFI (potassium-binding benzofuran isophthalate); Sigma-Aldrich, Heidenheim, Germany] diluted 2:1 with 20\% pluronic $\mathrm{F} 127$ for $10 \mathrm{~min}$ at $25^{\circ} \mathrm{C}$ according to the protocol by Costa et al. (2006). Three volumes of tetraethylammonium (TEA) buffer (in mM: sucrose 175, TEA-Cl 50, HEPES 10, pyruvate 5, malate 5, succinate 5, $\mathrm{P}_{\mathrm{i}}$ 5, EGTA 0.1 , and $\mathrm{MgCl}_{2} 0.5$ for experiments with conditional $\mathrm{Cx} 43$ knockout mitochondria; TEA-Cl 120, HEPES 10, succinate 10, $\mathrm{Na}_{2} \mathrm{HPO}_{4}$ 5, EGTA 0.1, $\mathrm{MgCl}_{2}$ 0.5, rotenone $5 \mu \mathrm{M}$, oligomycin $0.67 \mu \mathrm{M}$, pH 7.2 for experiments with Gap19) were added, and the mitochondria were incubated for $2 \mathrm{~min}$. Subsequently, the mitochondria were washed twice in isolation buffer and the protein concentration was measured using the Dc protein assay (Bio-Rad, Hercules, CA, USA). A sample of $200 \mu \mathrm{g}$ mitochondrial proteins (SSM and IFM) was incubated for 30 min at $4^{\circ} \mathrm{C}$ with $250 \mu \mathrm{M}$ of the $\mathrm{Cx} 43$-hemichannel blocking peptide Gap19 or under control conditions. In addition, untreated mitochondria from $\mathrm{Cx} 43^{\mathrm{fl} / \mathrm{fl}}$ and $\mathrm{Cx} 43^{\mathrm{Cre}-\mathrm{ER}(\mathrm{T}) / \mathrm{fl}}+4$-OHT mice (SSM) were studied. Mitochondria $(100 \mu \mathrm{g} / \mathrm{ml})$ were added to isolation buffer supplemented with $1 \mu \mathrm{g} / \mathrm{ml}$ oligomycin (inhibits the ATP synthase), $50 \mu \mathrm{M}$ glibenclamide (blocks the mitochondrial ATP-dependent potassium channel; control and conditional Cx43 knockout mice), and $1 \mu \mathrm{M}$ cyclosporin A (inhibits opening of the mitochondrial permeability transition pore; Gap19 experiments). The uptake of potassium into the mitochondria was induced by adding $140 \mathrm{mM} \mathrm{KCl}$. The PBFI fluorescence was measured in a Cary Eclipse Fluorescence Spectrophotometer (Varian, Mulgrave, Australia) at alternating excitation wavelengths of 340 (maximum potassium sensitivity of the probe) and $380 \mathrm{~nm}$ (isosbestic point of the probe), respectively, and an emission wavelength of $500 \mathrm{~nm}$ at $25^{\circ} \mathrm{C}$. The maximal slope of the PBFI fluorescence after the $\mathrm{KCl}$ pulse was determined, and the maximal slope for the control mitochondria was set to $100 \%$.

\section{WESTERN BLOT ANALYSIS}

Mitochondrial proteins were extracted in $1 \times$ Cell Lysis Buffer [Cell Signaling, Beverly, MA, USA, containing in mM: Tris 20, $\mathrm{NaCl}$ 150, ethylenediaminetetraacetic acid (EDTA) 1, EGTA 1, sodium pyrophosphate $2.5, \beta$-glycerolphosphate $1, \mathrm{Na}_{3} \mathrm{VO}_{4} 1$, phenylmethanesulfonyl fluoride (PMSF) $1,1 \mu \mathrm{g} / \mathrm{ml}$ leupeptin, $1 \%$ Triton $\mathrm{X}-100, \mathrm{pH} 7.5$, supplemented with complete protease inhibitors (Roche, Basel, Switzerland)]. After centrifugation at $13,000 \mathrm{~g}$ for $10 \mathrm{~min}$ at $4^{\circ} \mathrm{C}$ the supernatants were collected, and the protein concentrations were determined using the Dc protein assay (Bio-Rad, Hercules, CA, USA). Right ventricular or mitochondrial proteins $(20 \mu \mathrm{g})$ were electrophoretically separated on 10\% SDS-PAGE (sodium dodecyl sulfate-polyacrylamide gel electrophoresis) and transferred to nitrocellulose membranes. After blocking, the membranes were incubated with rabbit polyclonal anti-rat $\mathrm{Cx} 43$ (Invitrogen, Carlsbad, CA, USA) or rabbit-polyclonal anti-human manganese superoxide dismutase (MnSOD, Upstate, Lake Placid, NY, USA). After incubation with the respective secondary antibodies, immunoreactive signals were detected by chemiluminescence (SuperSignal West Femto Maximum Sensitivity Substrate, Pierce, Rockford, IL, USA) and quantified with the Scion Image software (Frederick, MD, USA).

\section{STATISTICS}

Data are presented as mean values \pm SEM. Western blot data and the velocities of mitochondrial potassium uptake were compared by Student's $t$-test.

\section{RESULTS}

The velocity of the mitochondrial potassium influx was measured in wild-type SSM under control conditions and after incubation with $250 \mu \mathrm{M}$ Gap19, a peptide that specifically inhibits Cx43-based hemichannels at plasma membranes, at excitation wavelengths of 340 and $380 \mathrm{~nm}$, respectively (Figure 1). In the presence of Gap19, the velocity of the mitochondrial potassium influx $(340 \mathrm{~nm})$ was reduced from $100 \pm 11.6 \%$ in control 
A

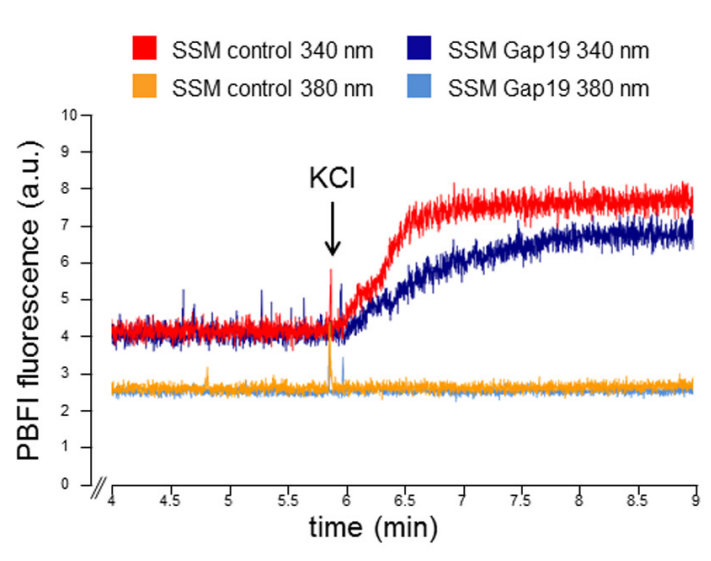

B

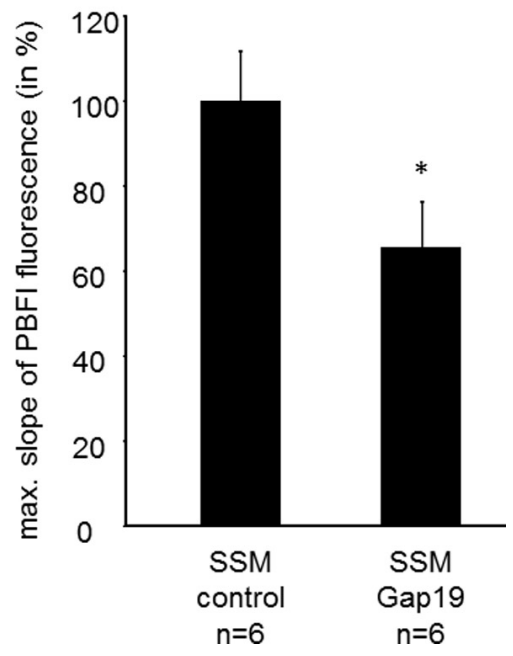

FIGURE 1 | Mitochondrial potassium uptake is decreased by Gap19. (A) Original traces showing PBFI fluorescence in arbitrary units (a.u.) before and after addition of $140 \mathrm{mM} \mathrm{KCl}$ of control- or Gap19-treated SSM at 340 and
$380 \mathrm{~nm}$ excitation and $500 \mathrm{~nm}$ emission, respectively. (B) Bar graphs represent the maximal slope of the PBFI fluorescence at $340 \mathrm{~nm}$ excitation and $500 \mathrm{~nm}$ emission of control and Gap19-treated mitochondria. ${ }^{*} p<0.05$. mitochondria to $65.5 \pm 10.7 \%(n=6, p<0.05)$. At $380 \mathrm{~nm}$ excitation, which represents the isosbestic point, the addition of $\mathrm{KCl}$ did not affect the PBFI fluorescence $(6.5 \pm 0.8 \%$ control vs. $7.8 \% \pm 1.0 \%$ Gap19 treatment, $n=6, p=n s$ ). In IFM, which do not contain Cx43, Gap19 treatment had no influence on the velocity of the mitochondrial potassium uptake ( $100 \pm 11.8 \%$ IFM control vs. $106.2 \pm 22.2 \%$ IFM Gap19-treated, $n=5$, $p=\mathrm{ns}$ ).

The Cx43 content in SSM was determined in $\mathrm{Cx} 43^{\mathrm{Cre}-\mathrm{ER}(\mathrm{T}) \mathrm{fl}}$ mice treated with $4-\mathrm{OHT}$ and in $\mathrm{Cx} 43^{\mathrm{fl} / \mathrm{fl}}$ control mice (Figures 2A,B). Western blot analysis demonstrated a reduction in mitochondrial $\mathrm{Cx} 43$ from $100 \pm 10.7 \%$ in $\mathrm{Cx} 43^{\mathrm{fl} / \mathrm{fl}}$ mice $(n=8)$ to $3.2 \pm 1.1 \%$ in $\mathrm{Cx} 43^{\mathrm{Cre}-\mathrm{ER}(\mathrm{T}) / \mathrm{fl}}+4$-OHT mice $(n=6, p<0.05)$. To exclude effects of 4 -OHT treatment on mitochondrial function, potassium influx was measured in mitochondria isolated from 4OHT-treated $\mathrm{Cx} 43^{\mathrm{fl} / \mathrm{fl}}$ and $\mathrm{Cx} 43^{\mathrm{Cre}-\mathrm{ER}(\mathrm{T}) / \mathrm{fl}}$ mice. The reduction of the mitochondrial $\mathrm{Cx} 43$ content was associated with a reduction in the maximal slope of the PBFI fluorescence from $100 \pm 11.2 \%$ in $\mathrm{Cx} 43^{\mathrm{fl} / \mathrm{fl}}+4$-OHT mitochondria $(n=9)$ to $66.6 \pm 5.5 \%$ in $\mathrm{Cx} 43^{\mathrm{Cre}-\mathrm{ER}(\mathrm{T}) / \mathrm{fl}}+4$-OHT mitochondria $(n=5, p<0.05$, Figure 2C).

\section{DISCUSSION}

The present study addressed the role of $\mathrm{Cx} 43$ in mitochondrial potassium uptake and demonstrated that both inhibition and genetic ablation of mitochondrial $\mathrm{Cx} 43$ reduce the velocity of the mitochondrial potassium influx specifically in SSM.
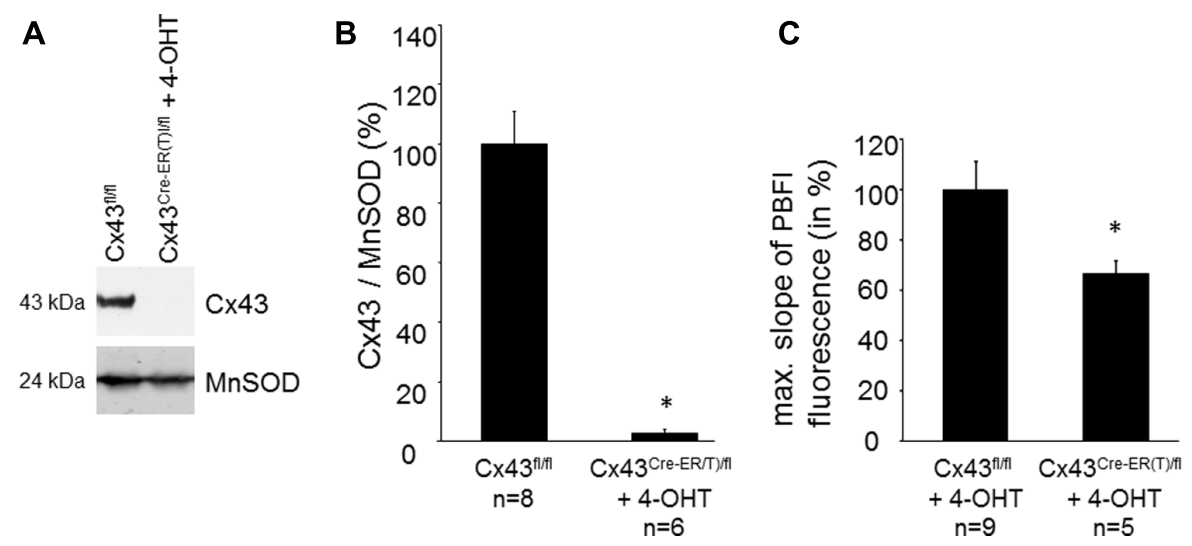

FIGURE 2 | Genetic ablation of $\mathbf{C x} 43$ reduces mitochondrial potassium uptake. (A) Western blot analysis was performed for $\mathrm{C} \times 43$ and the mitochondrial marker protein $\mathrm{MnSOD}$ on proteins isolated from SSM of $\mathrm{C} \times 43^{\mathrm{fl} / \mathrm{fl}}$ and $\mathrm{C} \times 43^{\mathrm{Cre}-\mathrm{ER}(\mathrm{T}) \mathrm{fl}}+4-\mathrm{OHT}$ mice. (B) Bar graphs represent the mitochondrial $\mathrm{C} \times 43$ content normalized to MnSOD in
$\mathrm{C} \times 43^{\mathrm{fl} / \mathrm{fl}}$ control mice, which were set to $100 \%$, and $4-\mathrm{OHT}$-treated

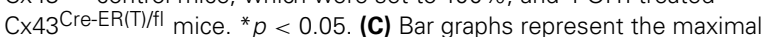
slope of the PBFI fluorescence at $340 \mathrm{~nm}$ excitation and $500 \mathrm{~nm}$ emission of 4-OHT-treated $\mathrm{C} \times 43^{\mathrm{fl} / \mathrm{fl}}$ and $\mathrm{C} \times 43^{\mathrm{Cre}-\mathrm{ER}(\mathrm{T}) / \mathrm{fl}}$ mitochondria. ${ }^{*} p<0.05$ 
The electrochemical gradient drives an inward potassium flux into mitochondria. For cardiac mitochondria, the ATP-dependent potassium ( mitoK $_{\mathrm{ATP}}$ ) channel is of major importance. This channel is activated by pharmacological agents such as diazoxide, whereas glibenclamide and ATP inhibit mitoK $K_{\text {ATP }}$ channel activity. The molecular identity of the mitoK $\mathrm{K}_{\mathrm{ATP}}$ channel has not yet been definitely established. However, data suggest mitochondrial localization of sarcolemmal potassium channel subunits (Ye et al., 2009), and, most recently, the contribution of the ROMK (renal outer medullary potassium channel) to the mitoK $\mathrm{ATP}_{\mathrm{AT}}$ channel (Foster et al., 2012).

Opening of the mitoK $\mathrm{K}_{\mathrm{ATP}}$ channel is important for the cardioprotection afforded by ischemic preconditioning (O'Rourke, 2004; Ardehali and O'Rourke, 2005), presumably via the formation of low amounts of reactive oxygen species that function as signaling molecules (Pain et al., 2000). Cx43 is involved in the cardioprotection conferred by mitoK $K_{\text {ATP }}$ channel opening, since reactive oxygen species formation and subsequent infarct size reduction by diazoxide are lost in Cx43-deficient mice (Heinzel et al., 2005).

The present study addressed the contribution of mitochondrial Cx43 to potassium influx. Experiments were performed in the presence of glibenclamide in order to allow the analysis of putative $\mathrm{Cx} 43$-based channels and separate them from effects of Cx43 on mitoK $\mathrm{K}_{\mathrm{ATP}}$ channels.

Previous data showed that in permeabilized mouse cardiomyocytes $\mathrm{Cx} 43$ contributes to mitochondrial potassium uptake (Miro-Casas et al., 2009). In this study, the Cx43 inhibitor $18 \alpha \mathrm{GA}$ was employed, and cardiomyocytes were used in which $\mathrm{Cx} 43$ had been replaced by $\mathrm{Cx} 32$. The aim of the present study was to investigate the importance of $\mathrm{Cx} 43$ for mitochondrial potassium refilling in more detail. Therefore, isolated mitochondria from control and conditional $\mathrm{Cx} 43$ knockout mice were used. The ablation of $\mathrm{Cx} 43$ was achieved by the administration of 4-OHT, which may impact on mitochondrial function, especially on mitochondrial calcium homeostasis (Lobaton et al., 2005). However, previous data demonstrated that the 4-OHT treatment used here has no influence on mitochondrial oxygen consumption (Boengler et al., 2012). To exclude putative effects of 4-OHT on mitochondrial potassium uptake, data obtained in mitochondria from conditional $\mathrm{Cx} 43$ knockout mice were compared to those obtained from 4-OHT-treated control mice. Our data demonstrate that mitochondria that contain only minimal amounts of Cx43 (about 3\% of the amount of control mitochondria) have a reduced velocity of potassium refilling. Therefore, our data confirm the importance of $\mathrm{Cx} 43$ for mitochondrial potassium uptake.

In addition to the chronic scenario of the $\mathrm{Cx} 43$ knockout mice, the acute situation was analyzed in which mitochondrial $\mathrm{Cx} 43$ was inhibited by Gap19. Gap19 is a peptide derived from nine

\section{REFERENCES}

Ardehali, H., and O'Rourke, B. (2005). Mitochondrial K(ATP) channels in cell survival and death. $J$. Mol. Cell. Cardiol. 39, 7-16. doi: 10.1016/j.yjmcc.2004.12.003

Boengler, K., Dodoni, G., RodriguezSinovas, A., Cabestrero, A., Ruiz-Meana, M., Gres, P., et al.
(2005). Connexin 43 in cardiomyocyte mitochondria and its increase by ischemic preconditioning. Cardiovasc. Res. 67, 234-244. doi: 10.1016/j.cardiores.2005.04.014 Boengler, K., Heusch, G., and Schulz, R. (2011). Mitochondria in postconditioning. Antioxid. Redox Signal. 14, 863-880. doi: 10.1089/ars.2010.3309

amino acids of the $\mathrm{Cx} 43$ cytoplasmic loop. This peptide inhibits single channel Cx43-hemichannel currents at plasma membranes but has no effect on gap junction channels or Cx40/pannexin-1dependent hemichannels as determined by calcium-induced ATP release. Gap 19 binds to the carboxy terminus of $\mathrm{Cx} 43$ and thereby prevents interactions between the carboxy terminus and the cytoplasmic loop (Wang et al., 2013). In isolated cardiomyocytes, Gap19 reduced cell swelling and cell death following simulated ischemia/reperfusion and reduced infarct size in mouse hearts in vivo (Wang et al., 2013). The specificity of Gap19 for Cx43-based hemichannels makes this peptide an excellent tool to study the role of $\mathrm{Cx} 43$ in mitochondrial potassium uptake. Since the carboxy terminus of mitochondrial $\mathrm{Cx} 43$ is directed toward the intermembrane space (Boengler et al., 2009), Gap19 does not have to enter the mitochondrial matrix in order to interact with $\mathrm{Cx} 43$.

In SSM isolated from wild-type mice, Gap19 induced a decrease in the velocity of mitochondrial potassium influx. In IFM, which do not contain Cx43 (Boengler et al., 2009), Gap19 had no effect, demonstrating the specificity of the peptide for Cx43.

The present experiments were performed in the presence of glibenclamide, which inhibits potassium fluxes through mitoK $\mathrm{K}_{\mathrm{ATP}}$ channels (Inoue et al., 1991; Paucek et al., 1992); therefore, it is unlikely that the delayed potassium influx in $\mathrm{Cx} 43$-deficient and Gap19-treated mitochondria is due to effects of Cx43 on these channels. However, several other channels also contribute to the mitochondrial potassium cycle, among them calcium-dependent potassium channels, the mitochondrial Kv1.3 potassium channel, and the two-pore potassium channel TASK-3 (for review, see Szabo et al., 2012). Since in the present study only total mitochondrial potassium fluxes were measured, it was not possible to distinguish whether mitochondrial potassium influx occurs through putative Cx43-based hemichannels or through an indirect modulation of the above mentioned potassium channels. Whether or not mitochondrial $\mathrm{Cx} 43$ forms a channel similar to those at the plasma membrane remains to be established. However, crosslinking studies of mitochondrial proteins with subsequent Western blot analysis for $\mathrm{Cx} 43$ revealed immunoreactive signals at a molecular weight typical for Cx43-based hexamers (Miro-Casas et al., 2009).

Taken together, both the genetic ablation of $\mathrm{Cx} 43$ in conditional knockout mice and the acute inhibition of mitochondrial Cx43 by Gap19 demonstrate reduced velocities of mitochondrial potassium uptake. These findings substantiate the impact of $\mathrm{Cx} 43$ on mitochondrial potassium fluxes.

\section{ACKNOWLEDGMENT}

This study was supported by the German Research Foundation (Schu 843/7-2).

Boengler, K., Ruiz-Meana, M., Gent, S., Ungefug, E., Soetkamp, D., Miro-Casas, E., et al. (2012). Mitochondrial connexin 43 impacts on respiratory complex I activity and mitochondrial oxygen consumption. J. Cell. Mol. Med. 16, 16491655. doi: 10.1111/j.1582-4934. 2011.01516.x
Boengler, K., Stahlhofen, S., Van De Sand, A., Gres, P., RuizMeana, M., Garcia-Dorado, D., etal. (2009). Presence of connexin 43 in subsarcolemmal, but not in interfibrillar cardiomyocyte mitochondria. Basic Res. Cardiol. 104, 141-147. doi: 10.1007/s00395009-0007-5 
Clarke, T. C., Williams, O. J., Martin, P. E., and Evans, W. H. (2009). ATP release by cardiac myocytes in a simulated ischaemia model: inhibition by a connexin mimetic and enhancement by an antiarrhythmic peptide. Eur. J. Pharmacol. 605, 9-14. doi: 10.1016/j.ejphar.2008.12.005

Costa, A. D., Quinlan, C. L., Andrukhiv, A., West, I. C., Jaburek, M., and Garlid, K. D. (2006). The direct physiological effects of mitoK(ATP) opening on heart mitochondria. Am. J. Physiol. Heart Circ. Physiol. 290, H406-H415. doi: 10.1152/ajpheart.00794.2005

Foster, D. B., Ho, A. S., Rucker, J., Garlid, A. O., Chen, L., Sidor, A., et al. (2012). Mitochondrial ROMK channel is a molecular component of mitoK(ATP). Circ. Res. 111, 446-454. doi: 10.1161/CIRCRESAHA.112.266445

Harris, A. L. (2002). Voltage-sensing and substate rectification: moving parts of connexin channels. J. Gen. Physiol. 119, 165-169. doi: 10.1085/jgp.119.2.165

Heinzel, F. R., Luo, Y., Li, X., Boengler, K., Buechert, A., Garcia-Dorado, D., et al. (2005). Impairment of diazoxide-induced formation of reactive oxygen species and loss of cardioprotection in connexin 43 deficient mice. Circ. Res. 97, 583-586. doi: 10.1161/01.RES.0000181171.65293.65 Inoue, I., Nagase, H., Kishi, K., and Higuti, T. (1991). ATP-sensitive K+ channel in the mitochondrial inner membrane. Nature 352, 244-247. doi: 10.1038/352244a0

Kozoriz, M. G., Church, J., Ozog, M. A., Naus, C. C., and Krebs, C. (2010). Temporary sequestration of potassium by mitochondria in astrocytes. J. Biol. Chem. 285, 31107-31119. doi: 10.1074/jbc.M109.082073

Lobaton, C. D., Vay, L., Hernandez Sanmiguel, E., Santodomingo, J., Moreno, A., Montero, M., et al. (2005). Modulation of mitochondrial $\mathrm{Ca} 2(+)$ uptake by estrogen receptor agonists and antagonists. $\mathrm{Br}$. J. Pharmacol. 145, 862-871. doi: 10.1038/sj.bjp.0706265

Miro-Casas, E., Ruiz-Meana, M. Agullo, E., Stahlhofen, S., RodriguezSinovas, A., Cabestrero, A., et al. (2009). Connexin43 in cardiomyocyte mitochondria contributes to mitochondrial potassium uptake. Cardiovasc. Res. 83, 747-756. doi: $10.1093 / \mathrm{cvr} / \mathrm{cvp} 157$

O'Rourke, B. (2004). Evidence for mitochondrial $\mathrm{K}+$ channels and their role in cardioprotection. Circ. Res. 94, 420-432. doi: 10.1161/01.RES.0000117583.66950.4

Pain, T., Yang, X. M., Critz, S. D., Yue, Y., Nakano, A., Liu, G. S., et al. (2000). Opening of mitochondrial $\mathrm{K}$ (ATP) channels triggers the preconditioned state by generating free radicals. Circ. Res. 87, 460-466. doi: 10.1161/01.RES.87.6.460

Paucek, P., Mironova, G., Mahdi, F., Beavis, A. D., Woldegiorgis, G., and Garlid, K. D. (1992). Reconstitution and partial purification of the glibenclamide-sensitive, ATPdependent $\mathrm{K}+$ channel from rat liver and beef heart mitochondria. J. Biol. Chem. 267, 26062-26069.

Schwanke, U., Konietzka, I., Duschin, A., Li, X., Schulz, R., and Heusch, G. (2002). No ischemic preconditioning in heterozygous connexin43deficient mice. Am. J. Physiol. Heart Circ. Physiol. 283, H1740H1742. doi: 10.1152/ajpheart. 00442.2002

Shintani-Ishida, K., Uemura, K., and Yoshida, K. (2007). Hemichannels in cardiomyocytes open transiently during ischemia and contribute to reperfusion injury following brief ischemia. Am. J. Physiol. Heart Circ. Physiol. 293, H1714H1720. doi: 10.1152/ajpheart. 00022.2007

Szabo, I., Leanza, L., Gulbins, E. and Zoratti, M. (2012). Physiology of potassium channels in the inner membrane of mitochondria. Pflugers Arch. 463, 231-246. doi: 10.1007/s00424-011-1058-7

Wang, N., De Vuyst, E., Ponsaerts, R., Boengler, K., Palacios-Prado, N., Wauman, J., etal. (2013). Selective inhibition of $\mathrm{Cx} 43$ hemichannels by Gap19 and its impact on myocardial ischemia/reperfusion injury. Basic Res. Cardiol. 108, 309. doi: 10.1007/s00395-012-0309-x

Ye, B., Kroboth, S. L., Pu, J. L., Sims, J. J., Aggarwal, N. T., Mcnally, E.
M., et al. (2009). Molecular identification and functional characterization of a mitochondrial sulfonylurea receptor 2 splice variant generated by intraexonic splicing. Circ. Res. 105, 1083-1093. doi: 10.1161/CIRCRESAHA.109.195040

Conflict of Interest Statement: The authors declare that the research was conducted in the absence of any commercial or financial relationships that could be construed as a potential conflict of interest.

Received: 04 March 2013; paper pending published: 25 March 2013; accepted: 17 May 2013; published online: 06 June 2013.

Citation: Boengler K, Ungefug E, Heusch G, Leybaert L and Schulz R (2013) Connexin 43 impacts on mitochondrial potassium uptake. Front. Pharmacol. 4:73. doi: 10.3389/fphar.2013.00073

This article was submitted to Frontiers in Pharmacology of Ion Channels and Channelopathies, a specialty of Frontiers in Pharmacology.

Copyright (c) 2013 Boengler, Ungefug, Heusch, Leybaert and Schulz. This is an open-access article distributed under the terms of the Creative Commons Attribution License, which permits use, distribution and reproduction in other forums, provided the original authors and source are credited and subject to any copyright notices concerning any thirdparty graphics etc. 